\title{
Vagueness and Family Resemblance ${ }^{1}$
}

\author{
HANOCH BEN-YAMI (25 JAN 2015)
}

\begin{abstract}
Meno: There will be no difficulty, Socrates, in answering your question, what is virtue? Let us take first the virtue of a man: he should know how to administer the state, and in the administration of it to benefit his friends and harm his enemies; and he must also be careful not to suffer harm himself. A woman's virtue, if you wish to know about that, may also be easily described: her duty is to order her house, and keep what is indoors, and obey her husband. Every age, every condition of life, young or old, male or female, bond or free, has a different virtue: there are virtues numberless, and no lack of definitions of them; for virtue is relative to the actions and ages of each of us in all that we do. And the same may be said of vice, Socrates. (Plato, Meno 71e-72a)
\end{abstract}

This is how Meno confidently answers Socrates' request to tell him what virtue is, an answer which is probably derived from Gorgias, as we gather from the dialogue and from Aristotle (Politics I 13, 1260a28). And Meno undeniably succeeds in giving us a good idea of what the ancient Greeks understood by virtue.

Socrates, however, is unsatisfied. With characteristic irony, he replies that he is remarkably fortunate, for while he asked for a single virtue Meno presented him with a swarm of them. What he would in fact like Meno to specify is the common nature that makes all these different virtues into virtue. Meno has difficulties understanding what Socrates means.

Meno's difficulty, which he shares with several of Socrates' interlocutors in Plato's dialogues, reflects a historical fact. What Socrates is interested in would today be called a definition, a specification of something common to all and only the cases to which the concept applies. And the demand for definitions as the correct form of explanation was indeed an innovation of the historical Socrates, who 'fixed thought for the first time on definitions' (Aristotle, Metaphysics I 6, 987b1). Plato adopted, elaborated and added his authority to this conception of definition as the only adequate form of the explanation of meaning.

Over the last 24 centuries, the sophisticated philosopher has generally sided with Plato and Socrates, rather than with Gorgias and Meno. Yet it is the latter who provide us with a better explanation of what was meant by virtue, as was noted already by Aristotle:

The temperance of a man and of a woman, or the courage and justice of a man and of a woman, are not, as Socrates maintained, the same; the courage of a man is shown in commanding, of a woman in obeying. And this holds of all other virtues, as will be more clearly seen if we look at them in detail, for those who say generally that virtue consists in a good disposition of the soul, or in doing rightly, or the like, only deceive themselves. Far better than such definitions is the mode of speaking of those who, like Gorgias, enumerate the virtues. (Politics I 13, 1260a21-28)

\footnotetext{
${ }^{1}$ Hanjo Glock, Peter Hacker, Severin Schroeder, Roger Teichmann, Natalia Waights Hickman and Sebastian Wyss were displeased with various points in earlier versions of this article; I hope they find this one more satisfactory.
} 
Despite this early observation, to explain a concept has almost invariably meant, from Plato to this day, to define it. If asked what we mean by a word or phrase, we are still expected to provide a necessary and sufficient condition for its application, to specify the common nature shared by all its instances.

Wittgenstein set himself against this conception of explanation early in the Nineteenthirties. At several places in his writings, he explicitly contrasts his method of explaining concepts with that of the Platonic Socrates. In his 'Dictation for Schlick', dating probably from December 1932, we find the following passage:

I can characterize my standpoint no better than by saying that it is the antithetical standpoint to the one occupied by Socrates in the Platonic dialogues. For if I were asked what knowledge is, I would enumerate instances of knowledge and add the words 'and similar things'. There is no shared constituent to be discovered in them since none exists. (VW 33; cf. BT 54, 56)

Similarly, slightly later, in the Blue Book, the Platonic Socrates is targeted again, this time in the context of emphasizing the deleterious influence that the quest for definitions has had in philosophy:

The idea that in order to get clear about the meaning of a general term one had to find the common element in all its applications has shackled philosophical investigation; for it has not only led to no result, but also made the philosopher dismiss as irrelevant the concrete cases, which alone could have helped him to understand the usage of the general term. When Socrates asks the question, 'what is knowledge?' he does not even regard it as a preliminary answer to enumerate cases of knowledge. (BB 19-20; cf. 26-7)

In his later writings, Wittgenstein developed, defended and used alternative modes of explanation, similar to those Meno and other interlocutors of Socrates provide in the Platonic dialogues.

In this respect, the rejection of the Socratic ideal of explanation is a return to a Pre-Socratic and Pre-philosophical lost innocence. The words 'explanation' and 'saying what $\mathrm{X}$ is' are brought back from their philosophical to their everyday, pre-philosophical use (PI $\ 116)$. A picture of what an explanation of meaning must be like held us captive for centuries (PI $\left.\int 115\right)$; the realisation that explanations of the sort supplied by Socrates' interlocutors are legitimate and often the most appropriate ones is at the same time a release from that picture. The latter explanations are also quite often readily available-'I am making it easier and easier for myself in philosophy', Wittgenstein remarks in this context in The Big Typescript (56; cf. PG 121). The philosophical project of providing a definition is eliminated, and it is not replaced by any other project of comparable difficulty. The aforementioned realisation is in this respect an instance of philosophical therapy, which gives philosophy peace by eliminating its obsessive quest for definitions.

The legitimacy of the pre-Socratic form of concept explanation in philosophy is demonstrated by the use Wittgenstein himself makes of it while introducing new terms in the course of his investigations. Language game, for instance, is explained as follows:

We can also think of the whole process of using words [for communication between a builder and an assistant as described in Section 2] as one of those games by means of which children learn their native language. I will call these 
games "language-games" and will sometimes speak of a primitive language as a language-game.

And the processes of naming the stones and of repeating words after someone might also be called language-games. Think of certain uses that are made of words in games like ring-a-ring-a-roses.

I shall also call the whole, consisting of language and the activities into which it is woven, a "language-game". (PI $\int 7$ )

Instead of a necessary and sufficient condition, we are given a few examples, intended to make clear what the new phrase means. Similarly, what is meant by 'family resemblance' is explained by means of a specific example, that of a game (PI \$S 66-67). And later in the work, the explanation of 'noticing an aspect' is again through an example:

I observe a face, and then suddenly notice its likeness to another. I see that it has not changed; and yet I see it differently. I call this experience "noticing an aspect”. (PI xi \113)

This mode of explanation is consistent with Wittgenstein's methodology and contrasts with the traditional way of explaining and introducing concepts by means of definitions.

Wittgenstein's neologisms are among the philosophical terms introduced during the twentieth century that have had the widest use, in philosophy as well as in other disciplines. This shows that explanations not by means of definitions are no obstacle to the coining of useful concepts; and if, with Wittgenstein, we identify meaning with use (PI $\left.\int 43\right)$, it also shows that such explanations are no obstacle to the coining of meaningful concepts.

Wittgenstein was not the first to either criticise the Socratic demand for definition or to develop and defend alternative ways of explaining concepts. Yet he was the first who has done this in such detail and scope and with far reaching conclusions. We saw that Aristotle preferred Gorgias's explanation of virtue to Plato's; but this preference was limited in scope, and Aristotle generally provides definitions by means of genus and differentia, adopting Plato's method in the Sophist and Statesman. Other philosophers who described alternative modes of concept formation usually saw these as inferior from a logical or epistemological point of view to definitions. Spinoza, for instance, distinguishes between different ways our concepts or ideas are formed, and suggests a physiological account of the origin of concepts such as 'man', 'horse' and 'dog' through the accumulation of images in our brain. ${ }^{2}$ It seems that these cannot be defined and should also inevitably exhibit some kind of vagueness. But these inadequate and confused ideas', the source of endless controversies among philosophers, are involved only in the lowest kind of cognition and are the cause of our mistakes (Ethics II 40 Scholia I \& II, 41).

A different approach was taken by Dugald Stewart. In his Philosophical Essays of 1810, he criticised the preference for definitions by means of genus and differentia, and developed an alternative account of concepts that has points in common with Wittgenstein's ideas of family resemblance. ${ }^{3}$ Later in the century, William Whewell, in his History of Scientific Ideas, contrasted classification in mathematics with that in natural

\footnotetext{
2 Although what Spinoza understood by ideas only partly overlaps with what we understand by concepts, I am interested here in his 'ideas' only in so far as the properties he ascribes to them can be seen as reflecting the logical properties of the corresponding concepts.

${ }^{3}$ For more on Stewart see (Baker and Hacker 2005a, 207-208).
} 
history and all other 'speculations'. Unlike mathematical classes, natural ones are determined not by a definition but by a 'type':

The class is steadily fixed, though not precisely limited; it is given, though not circumscribed; it is determined, not by a boundary line without, but by a central point within; not by what it strictly excludes, but by what it eminently includes; by an example, not by a precept; in short, instead of Definition we have a Type for our director. (Whewell 1858, 121)

This kind of classification inevitably gives rise to vagueness, and with it to indeterminate boundary cases. Such indeterminacy, however, 'would not destroy the reality of the generic groups, any more than the scattered trees of the intervening plain prevent our speaking intelligibly of the distinct forests of two separate hills' (Ibid., 122).

But these early insights did not have much impact. Mill, although impressed by these passages of Whewell's work, criticised him on various points and claimed that between the kinds which are the object of natural classification 'there is an impassable barrier; and what we have to seek is, marks whereby we may determine on which side of the barrier an object takes its place' (Mill 1882, Bk. 4 Chap. VII \$S 3-4). Frege, whose work served as Wittgenstein's point of departure on these issues as on many others, thought that every concept should be sharply defined, and denied the possibility of a vague concept:

A definition of a concept (of a possible predicate) must be complete; it must unambiguously determine, as regards any object, whether or not it falls under the concept $[. .$.$] If we represent concepts in extension by regions on a plane, this is$ admittedly a picture that may be used only with caution, but here it can do us good service. To a concept without sharp boundary there would correspond a region that had not a sharp boundary-line all round, but in places just vaguely faded away into the background. This would not really be a region at all; and likewise a concept that is not sharply defined is wrongly termed a concept. (The Basic Laws of Arithmetic, Vol. II (1903) \56; translation based on (Frege $1960,159))^{4}$

Similarly, we find the early Wittgenstein brooding over the question, 'could it be possible that the sentences in ordinary use have, as it were, only an incomplete sense?' He finds the question, whether when one says 'The book is lying on the table' this really has a completely clear sense, extremely important, apparently betraying his suspicion that it has not. But after some deliberations he insists: 'It seems clear that what we MEAN must always be "sharp".' (NB 67-8) The Tractatus manifests this position in its claim that 'the requirement that simple signs be possible is the requirement that sense be determinate' (3.23). This is the position Wittgenstein will reject in his later work.

The discussion in the Philosophical Investigations of determinacy of sense, definition, explanation of concepts and related issues begins with the claim that all the phenomena that we call 'language' have no one thing in common, no shared essence, in virtue of which we use the same word for all, but that there are many different kinds of affinity between them on account of which we do that (PI $₫ 65$ ). The standard Platonic view of concepts is thus mentioned in order to be rejected. The discussion continues with an examination of a different concept, that of a game (PI $\ 66$ ), which is of course related to that of

\footnotetext{
${ }^{4}$ For more on Frege on vagueness see (Puryear 2013).
} 
language game and thus to that of language. If we examine all that we call 'games' we shall find affinities and resemblances, but nothing common to all in virtue of which we call all 'games'. Not all are entertaining (and there are entertaining activities which are not games); winning and losing are not always part of a game, neither is competition (Solitaire, The Sims, the Israeli Matkot game; and, again, winning and losing exist in war, which is no game); the objective need not be arbitrary or lack significance outside the game (consider the games teachers use in class); and so on. ${ }^{5}$ We find nothing in common to all and only games, but rather a complicated network of resemblances, overlapping and criss-crossing.

I can think of no better expression to characterize these resemblances than 'family resemblances'; for the various resemblances between members of a family - build, features, colour of eyes, gait, temperament, and so on and so forth overlap and criss-cross in the same way. - And I shall say: 'games' form a family. (PI $\left.\int 67\right)$

Wittgenstein immediately proceeds with an assault on the citadel of crystalline accuracy, mathematics, targeting its most important concept, that of a number. We call something 'number', he suggests, because it has a direct affinity with several things that have hitherto been called 'number', and thus an indirect affinity with other things that we also call 'numbers'. Complex numbers have this affinity with the real numbers, the real numbers have it with the rational, the rational with the natural, the transfinite with the finite, and so on. Thus, the kinds of number also form a family. No place is safe from this critique of the Platonic view.

Later in the Investigations, Wittgenstein provides a meticulous analysis of our concept of reading and related concepts, showing how hopeless it is to find anything common to all and only cases of reading and how these different cases relate to each other by a complicated network of resemblances (PI $\iint$ 156-178). He concludes that 'we also use the word "read" for a family of cases. And in different circumstances we apply different criteria for a person's reading.' (PI \164) Although subsequent literature on family resemblance has focused on the concept of game, Wittgenstein's analysis of that of reading is the most detailed example in the PI of the failure of the idea that there must be a common essence to all cases in the extension of a concept, as well as of the way in which a complex web of resemblances determines a concept.

One might claim that our failure to find something in common to all and only games does not prove that they have no such thing in common. However, Wittgenstein writes that we do not see any such common element and that we use the same name for all instances not because they have something in common. This formulation is not committed to the non-existence of a common essence but rather to the irrelevance of such a commonality to the use of an expression and therefore to its meaning. All the same, the inevitable conclusion to be drawn from Wittgenstein's examination of specific cases is that such a common essence often does not exist.

The fact that an expression is applied on the basis of a complex web of resemblances does not make it ambiguous or polysemous: the complex web may still yield a unified concept. We extend a concept the way in spinning a thread we twist fibre on fibre, and the thread produced in this way is strong not because some one fibre runs through its whole length but because its many fibres overlap (PI $\left.\int 67\right)$. We may of course divide games into board games, card games, ball games and so on; or into competitive and non-competitive ones, etc. But this division into sub-concepts does not show that

\footnotetext{
${ }^{5}$ Some of the examples, here and below, are not taken from Wittgenstein's work.
} 
the original concept of game lacks unity any more than the division into even and odd numbers shows that the concept of natural number does.

One might try to criticise the idea that a web of resemblances can determine a concept as follows: if we extended a concept by means of resemblances and affinities then, since war resembles a game (winner and loser, skill, strategies...) it should or at least could be considered a game. However, war is not a game, so a web of resemblances cannot determine a concept.-The answer to this criticism is that we typically introduce several mutually exclusive concepts when dividing a conceptual field. We introduce game and war, playing and quarrelling, as different from each other, and in this way we also determine boundaries between them, albeit vague ones.

A concept is vague if it has indeterminate boundary cases, namely cases where its usage and explanation provide reasons for as well as against applying it, without these reasons being sufficient either way. Colour concepts, for instance, are vague, for the samples we use to explain or decide which colours are red and which are orange, say, leave some shades hovering between the two. However, colour concepts are not family resemblance ones: they do not have a plurality of criteria or of dimensions of resemblance that determine their application. A family resemblance concept, on the other hand, need not admit of a prototypical sample by means of which its application could be determined. So family resemblance concepts, although typically vague, are but one kind of vague concepts.

However, family resemblance concepts typically being vague, and philosophersFrege and Wittgenstein's former self included-having generally been hostile to vagueness, Wittgenstein finds it necessary to defend the legitimacy of vague concepts.

Wittgenstein's treatment of vagueness, although illuminating in several respects, might disappoint some contemporary philosophers interested in the subject. For the last forty odd years, the philosophical discussion of vagueness has focused on the Sorites, the ancient paradox of the heap: if we remove one grain from a heap of grains, the remaining collection of grains is still a heap. It thus seems to follow that never mind how many times we repeat this process, the remaining collection must always be a heap. Yet we shall end up with a single grain, which is no heap. We apparently proved a false conclusion by a sound argument. ${ }^{6}$

Wittgenstein does not mention the Sorites in the Philosophical Investigations. He does mention the paradoxical situation in his writings from the early thirties (BT $34=$ PG Part I Appendix 8, 236-240; see also PR JS 211-213), but even there he does not try to resolve the paradox. In The Big Typescript he describes a hypothetical attempt to determine, by a series of questions about the classification of cases around the borderline of a vague concept, a sharp boundary for that concept, and the way the attempt would fail by yielding inconsistent results. Apparently, he subsequently came to realise that such procedures, forcing us to use vague concepts in circumstances in which they are useless, cannot shed much light on the logic of such concepts, and this thought experiment disappeared from his later writings. ${ }^{7}$ Yet this is the closest he gets to a discussion of the Sorites. A resolution of the paradox along Wittgensteinian lines is perhaps possible (Ben-Yami 2010), but none is found in Wittgenstein's own writings.

I quoted Frege's assertion that 'a concept that is not sharply defined is wrongly termed a concept'. Since Wittgenstein now sees 'the concept of a game [as] a concept

\footnotetext{
${ }^{6}$ For a survey of recent literature, see the entries 'Sorites Paradox' and 'Vagueness' in The Stanford Encyclopedia of Philosophy.

${ }^{7}$ His dismissal of this hypothetical experiment is in contrast with its painstaking discussion by some contemporary philosophers, who are convinced that this 'forced march' could offer us insights into the logic of vague concepts. See (Raffman 1994) and (Shapiro 2006). For a more detailed and a more sympathetic discussion than mine of these passages from Wittgenstein, see (Faulkner 2010).
} 
with blurred edges', Frege's approach should be exposed as misguided. Moreover, vague concepts should be shown not to be a kind of second-best option, acceptable only where sharply defined ones are unavailable. To that end, Wittgenstein first compares vague concepts to a photograph that is not sharp, which may still be a picture of a person. Moreover, he notes that a picture that is not sharp might be just what we need, with no advantage to be gained by replacing it with a sharp one (think of a picture of an approximate triangle, or of a bridge in the mist). Frege's claim that a concept without a sharp boundary corresponds to a region with no sharp boundary-line, which is not really a region, is also critically considered: since to have a meaning is, for Wittgenstein, to have a use, Frege's claim comes down to the claim that we couldn't do anything with such a concept or with such a region. But the request, 'Stay roughly here', where the region is specified not by drawing a boundary but just by a pointing gesture, may work perfectly well. So vagueness is no obstacle to use, nor therefore to meaning. (PI \ 71)

Pushing his criticism further, Wittgenstein investigates what it could mean to replace this apparently inexact explanation by an exact one. Drawing a boundary-line around a region with chalk is still 'inexact', since the line has breadth. A colour edge would be more exact, but we need to lay down what is to count as overstepping it: how and with what instruments it is to be ascertained. And so on. It is clear that such exactness has no function when we say, 'Stay roughly here'; it is running idle. And, having no use, it does not contribute to the meaning of what is said (PI $\int 88$ ).

In fact, we have been abusing our concept of exactness in the previous paragraph. We know what it means to set a pocket-watch to the exact time, and the remark, 'You should come to dinner more punctually; you know it begins at one o'clock exactly' makes perfectly good sense. We call something 'inexact' if it attains its goal less perfectly than does the more exact, so whether an explanation or description is exact depends on our goal. If I say, 'The ground was quite covered with plants', I might explain what I mean by making a drawing and remarking, 'It looked exactly like this'. So to the extent that talk about exactness makes sense, the use of vague concepts is no obstacle to exactness, for we can use them to attain our goal as perfectly as we need (PI $\iint 70,88$ ).

Wittgenstein discusses an additional aspect of indeterminacy of sense, which he does not always clearly distinguish from the vagueness discussed above. Many of our concepts are unbounded in various ways: for some possible circumstances, nothing is determined by their explanations and use on how to apply them. To use Wittgenstein's example, there are no rules for how high or how hard one may throw the ball in tennis, yet tennis is a game for all that (PI $\ 68$ ). By contrast, if we make a gesture towards a region of roughly one meter in diameter and say 'Stay roughly here', then this determines, although not sharply, the boundaries of a region. But the rules of tennis say nothing about how high one may throw the ball. It is not that we know that one meter is permissible while one hundred meters are not: this height has never been a factor in the game and there are no rules concerning it. In this respect, the concept of a legitimate move in tennis remains unregulated. If this height ever becomes a factor we shall have to invent appropriate rules, but these would not sharpen an earlier practice the way a scientific definition of one gram might do. (See also Wittgenstein's chair example, PI $\left.\int 80.\right)$

This is the way, claims Wittgenstein, in which we use the concepts of number and game. When the complex numbers and the transfinite cardinals were invented, what we already counted as numbers did not determine whether these new mathematical entities should also be considered as such. It is not that they were on some vague borderline separating numbers from other mathematical creatures: they constituted a new mathematical dimension, and our use had to be extended towards it. Such new cases might be similar in many respects to old ones, and consequently there may be natural 
decisions and even obvious ones to make on how to apply our concepts to them; yet even then, these decisions extend our concepts.

The boundaries of the concept of number as currently used in mathematics could indeed be made rigid, and we would then not extend it to new cases that might come up. (In that case, we would have some sort of a family resemblance concept with a determinate sense.) But although the possibility is open to us, this is not how we use the concept of number nor is there any need to use it in such a way. The fact that the use of a word is not everywhere bounded by rules does not make it unregulated. Moreover, it seems this cannot be done for the concept of game, whose current extension, unlike that of the mathematical concept of number, has vague boundaries (PI $\int 68$ ).

Concepts of this kind, for which the question of applicability in new, unforeseen directions might always arise, can be called, following Waismann, open textured (1951; the term was suggested by Kneale). 'Most of our empirical concepts are not delimited in all possible directions', writes Waismann. Even for scientific concepts that seem to be defined with absolute precision,

we can never exclude altogether the possibility of some unforeseen situation arising in which we shall have to modify our definition. Try as we may, no concept is limited in such a way that there is no room for any doubt. [...] We tend to overlook the fact that there are always other directions in which the concept has not been defined. And if we did, we could easily imagine conditions which would necessitate new limitations. [...] That is what is meant by the open texture of a concept. ${ }^{8}(120)$

Waismann is careful to distinguish open texture from vagueness. 'Heap' and 'pink' are vague because they are 'actually used in a fluctuating way'-apparently he means that differing classifications of borderline cases can and do occur. An open textured term, by contrast, need not have this 'fluctuating' use. Moreover, 'vagueness can be remedied by giving more accurate rules, open texture cannot' (Ibid.). ' Waismann's 'open texture' can thus be used to draw attention to this special, distinct phenomenon of indeterminacy of sense, typical of family resemblance concepts.

The Platonic view of meaning as specified by a definition has as a consequence a clear view on knowledge of meaning: to know what a word means is to be able to define it. But this view of knowledge comes at a price. From the Socratic dialogues on, people have failed to supply definitions to most words they have been using; it follows that they did not know the meaning of these words. On the other hand, if one indeed doesn't know the meaning of a word one uses, how could one possibly succeed in defining it?A paradox of analysis seems to lurk behind the Platonic view. As a response, views on knowledge as recollection (Plato), on implicit or latent knowledge (recent philosophy of language and linguistics) and other similar views have been developed.

\footnotetext{
${ }^{8}$ Waismann uses the idea of open texture to criticise verificationism and phenomenalism, but his characterisation of open texture quoted here is independent of this criticism or of any other use he makes of the idea.

${ }^{9}$ Despite this distinction between vagueness and open texture which exists in Wittgenstein's and Waismann's works, recent literature on vagueness has tended to ignore the distinction and in fact the phenomenon that the term 'open texture' is here used to capture. Shapiro, for instance, borrows the phrase 'open texture' from Waismann but uses it in order to characterise vagueness and the 'fluctuating' use of vague terms like 'heap' and colour words (2006, \2.2 and footnote \#5 on page 11). Although Shapiro is aware that his use of the term departs from Waismann's (Appendix, 210ff), this departure only serves to obscure the fact that open texture characterises a separate and important variety of indeterminacy of sense.
} 
Having rejected this standard view of the nature of meaning, Wittgenstein has to address the issue of knowledge of meaning. He first remarks on it in section 69 , while discussing concepts' lack of boundaries:

How would we explain to someone what a game is? I think that we'd describe games to him, and we might add to the description: "This and similar things are called 'games'." And do we know any more ourselves? Is it just that we can't tell others exactly what a game is? - But this is not ignorance. We don't know the boundaries because none have been drawn.

The focus of this section is the lack of boundaries, but it already contains the view that an explanation by means of examples is a legitimate way of expressing knowledge of meaning. 'Giving examples is here not an indirect way of explaining - in default of a better one.' (PI $\left.\int 71\right)$ And such explanations are obviously readily available to anyone who uses the concept of game correctly. They might of course be misunderstood, and some might be clearer than others-but this is also the case with any definition or other general explanation.

Wittgenstein turns again to the nature of knowledge and explanation of meaning in section 75 . He mentions the view that this knowledge of meaning, which we might not be able to express, is equivalent to an unformulated definition which, once formulated, we would be able to recognize as expressing our knowledge. He is evidently opposed to this view, which he contrasts with his own position, again exemplified by the concept of game:

Isn't my knowledge, my concept of a game, completely expressed in the explanations that I could give? That is, in my describing examples of various kinds of game, showing how all sorts of other games can be constructed on the analogy of these, saying that I would hardly call this or that a game, and so on.

Our knowledge is completely expressed by these explanations; there is nothing latent or implicit in it, nothing unconscious awaiting some kind of Platonic recollection. We again see how philosophical theories were engendered by a mistaken view of knowledge of meaning and how the need for any such theorising is eliminated once this view is corrected.

A family resemblance concept has to be explained by means of examples or instances. Some instances of a family resemblance concept might be more typical, in some sense of typicality, than others, but so might be instances of other kinds of concept. And even the typicality of instances of a family resemblance concept might be not a result of the logical character of the concept but of factors of relative frequency, say, or of some other kind of prominence. A policewoman might not represent a typical grandmother, and 4 might be more typical as an even number than 17101962; but these kinds of typicality have no function in the explanation of the concept of grandmother or of even number, both concepts being explained by means of a definition. ${ }^{10}$ Having typical instances is thus in itself no indication that a concept is a family resemblance one. What does show this logical character of a concept is the role of instances in explaining its meaning. ${ }^{11}$

\footnotetext{
10 Although the concept of a mother, on which that of a grandmother depends, might have an open texture: think of the new possibilities of gestational mother versus genetic mother.

${ }^{11}$ Eleanor Rosch, inspired by Wittgenstein's idea of family resemblance, tried to show by means of experiments that this is indeed the structure of some of our concepts. But not having distinguished typicality from role in explanation, she merely asked her subjects to grade 'how good an example of a
} 
The considerations above on the nature of concepts are among those that lead Wittgenstein to reconsider the nature of logic itself (PI $\left.\int 89\right)$. He first describes his former way of thinking, which to a large extent he inherited from the earlier philosophical tradition. Logic, the essence of thought and language, presents the order of possibilities, which must be utterly simple, a purest crystal. Therefore, where there is sense, there must be perfect order. A sentence must have determinate sense, he echoes the Tractatus 3.23, for an indeterminate sense would be like a boundary that is not sharply defined, which is not really a boundary (this time echoing Frege). There cannot be any vagueness in logic, for the ideal must exist in reality. (PI \$S 96-101).

But all this was misguided. The idea of perfect order was like a pair of glasses fixed on our nose through which we saw whatever we looked at. The perfect order was never in linguistic reality but in our mode of representation of that reality, in our logical constructions. Moreover, since reality failed to comply, we became dissatisfied with what are ordinarily called 'sentences', 'words' or 'signs' and looked in vain for their hypothetical logically pure correlates (as is still so often done in philosophy of language and formal semantics). We should instead take these glasses off and turn the whole inquiry around, by returning to the rough ground. Philosophy of logic should speak of sentences and words in the same sense in which we speak of them in ordinary life. The prejudice of crystalline purity should be dismissed, and we should realise that what we call 'sentence' and 'language' do not have the formal unity we imagined them to have but are a family of structures more or less akin to one another, with concepts that have indeterminate senses and vague boundaries. (PI \$S 103-108) The rejection of the Platonic view of concepts culminates in a revision of our conception of logic itself.

A tradition of two and a half millennia with its habits of thought cannot be destroyed at one fell swoop, no matter how thorough. And indeed, the Platonic view of concepts and their explanation continues to thrive in philosophy, Wittgenstein's assault notwithstanding. Hordes of philosophers have wasted much time in vain attempts to define the concept of game and show that Wittgenstein was wrong, yet their failures did not help convince them and others that he might have been right.

Some philosophers did of course view Wittgenstein's criticisms and development of alternative paradigms more approvingly. We saw above his influence on Waismann. An attitude towards vagueness which probably was also inspired by Wittgenstein's is apparent throughout Ryle's work as well. For instance, when discussing the intellect, he dismisses the demand for necessary and sufficient conditions for an activity being intellectual:

But, after all, does it matter if all attempts at giving a hard-edged definition of 'intellectual' and 'thought' break down somewhere or other? We know well enough how to distinguish urban from rustic areas, games from work, and spring from summer, and are unembarrassed by the discovery of undecidable marginal cases. We know that solving a mathematical problem is an intellectual task, hunting the thimble is a non-intellectual task, while looking for an apposite rhyme is a halfway house. [...] Our daily use of the concepts of the intellect and

category various instances of the category are' and how well they fit their image of the category, and told them not to worry why they feel so. In this way, what she in fact showed was only that the instances of some concepts might vary in their typicality (Rosch 1975). As was said above, this is true of concepts of other kinds as well; and indeed, Armstrong and her colleagues (1983) replicated Rosch's results with other kinds of concept. In order to determine whether a concept is a family resemblance one we have to examine how it is explained, and not whether some of its instances are more typical than others. 
of thought is unembarrassed by the discovery of a moderate number of borderline cases. (1949, 258-9)

An interesting instance of what might well be Wittgenstein's influence is provided by one of the important controversies of twentieth-century philosophy, that between Quine and Grice and Strawson on the viability of the analytic-synthetic distinction. Quine tried to clarify this distinction, and with it other semantic concepts such as 'meaning the same as', by means of a general definition. Having failed to find a satisfactory definition that does not rely on concepts from the same semantic family, he rejected the analytic-synthetic distinction: 'That there is such a distinction to be drawn at all is an unempirical dogma of empiricists, a metaphysical article of faith.' $(1953,37)$ Quine was clearly philosophising within the Platonic tradition, which considers the definition as the only legitimate form of explanation of a concept, and his commitment to it led him to reject the meaningfulness of the concept of synonymy and with it of related concepts, which is absurd. Grice and Strawson, by contrast, rejected that tradition and attempted to clarify one of the relevant semantic concepts, that of logical impossibility, by means of a concrete example which relates it to an epistemic concept, that of understanding. If someone asserted, 'My neighbour's three-year-old child is an adult', which is logically impossible, and appeared to mean it literally, we would simply not understand him (1956, 201-206). This illuminating explanation is, methodologically, clearly Wittgensteinian. As Strawson had closely read the Investigations shortly earlier for the critical study of the book he published in Mind (1954; cf. esp. 141-142), it is quite possible that we hear Wittgensteinian echoes in this response to Quine.

But such echoes are seldom heard in more recent philosophy. Many philosophers are as desperate for definitions as ever. Some even deny that any concepts are vague: concepts that are apparently vague are supposed to be sharp, as Wittgenstein insisted while viewing reality through his Ideal glasses in his twenties, and their apparent vagueness merely reflects our ignorance of their meaning. In addition, one frequently comes across far-fetched cases which are put forward as counterexamples that show a certain explanation of a given concept to be wrong. Wittgenstein, by contrast, would consider more complex cases not as showing that explanations that apply to the basic cases are wrong, but as presupposing such simple explanations while requiring their elaboration:

When one describes simple language-games in illustration, let's say, of what we call 'motive' of an action, then more involved cases keep on being held up before one, in order to show that our theory doesn't yet correspond to the facts.

Whereas more involved cases are just more involved cases. For if what were in question were a theory, it might indeed be said: It's no use looking at these special cases, they offer no explanation of the most important cases. By contrast, the simple language-games play a quite different role. They are poles of a description, not a ground-floor of a theory. (RPP I $\int 633$; translation slightly altered)

Wittgenstein's conception of explanation as expressed in this passage, and with it his related ideas on the indeterminacy of sense, on vagueness and on family resemblance are foreign to most contemporary discussions in analytic philosophy. ${ }^{12}$

\footnotetext{
${ }^{12}$ For the issues covered in this article see also (Schroeder 2006), \4.2 and the relevant entries in (Glock 1996). For a detailed discussion see (Baker and Hacker 2005a) Essay XI, and the exegesis in (Baker and Hacker 2005b) Chap. 3.
} 
References

Aristotle. 1941. Metaphysics (translated by W. D. Ross) and Politics (translated by Benjamin Jowett). In The Basic Works of Aristotle. Edited by Richard McKeon. New York: Random House.

Armstrong, S. L., L. R. Gleitman and H. Gleitman 1983. What Some Concepts Might Not Be. Cognition 13: 263-308.

Baker, G. P. and P. M. S. Hacker. 2005a. Wittgenstein: Understanding and Meaning. Part I: Essays. Second, extensively revised edition by P. M. S. Hacker. Oxford: Blackwell.

Baker, G. P. and P. M. S. Hacker. 2005b. Wittgenstein: Understanding and Meaning. Part II: Exegesis $\iint 1-184$. Second, extensively revised edition by P. M. S. Hacker. Oxford: Blackwell.

Ben-Yami, H. 2010. A Wittgensteinian Solution to the Sorites. Philosophical Investigations 33: 229-244.

Faulkner, Nadine. 2010. Wittgenstein's Philosophical Grammar: A Neglected Discussion of Vagueness. Philosophical Investigations 33: 159-183.

Frege, Gottlob. 1960. Translations from the Writings of Gottlob Frege. Edited and trenaslated by Peter Geach and Max Black. Oxford: Blackwell.

Glock, Hans-Johann. 1996. A Wittgenstein Dictionary. Oxford: Blackwell.

Grice, Paul and Peter Strawson. 1956. In Defense of a Dogma. Reprinted Grice, Paul 1989. Studies in the Way of Words. Harvard University Press, 196-212.

Raffman, Diana. 1994. Vagueness without Paradox. Philosophical Review 103: 41-74.

Mill, John Stuart. 1882. A System of Logic, Ratiocinative and Inductive. Eighth edition. New York: Harper \& Brothers.

Plato. Meno. Translated by Benjamin Jowett.

Puryear, Stephen. 2013. Frege on Vagueness and Ordinary Language. The Philosophical Quarterly 63: 120-140.

Quine, Willard van Orman. 1953. Two Dogmas of Empiricism. In his From a Logical Point of View. Second edition 1961. Harvard University Press, 20-46.

Rosch, E. and C. B. Mervis. 1975. Family Resemblances: Studies in the Internal Structure of Categories. Cognitive Psychology 7(4): 573-605.

Ryle, Gilbert. 1949. The Concept of Mind. $60^{\text {th }}$ anniversary edition, 2009. London and New York: Routledge.

Schroeder, Severin. 2006. Wittgenstein: The Way Out of the Fly-bottle. Cambridge: Polity Press.

Shapiro, Stewart. 2006. Vagueness in Context. Oxford University Press.

Spinoza, Benedictus de. 1677. Ethics. English translation by S. Shirley in Spinoza 2002. Complete Works. Edited by M. L. Morgan. Indianapolis: Hackett.

Stewart, Dugald. 1810. Philosophical Essays. Edinburgh: Creech and Constable.

Strawson, Peter. 1954. Wittgenstein's Philosophical Investigations. Reprinted in his 1974. Freedom and Resentment and other Essays. London: Methuen, 133-168.

Waismann, Friedrich. 1951. Verifiability. In Flew, Antony (ed.) Logic and Language (First Series). Oxford: Blackwell, 117-144.

Whewell, William. 1858. History of Scientific Ideas. Volume II. Third edition. London: John W. Parker and Son.

Zalta, Edward N. (ed.) The Stanford Encyclopedia of Philosophy. Stanford University. URL: http://plato.stanford.edu/. 